\title{
Per Hundred Thousand
}

National Cancer Institute

\section{Source}

National Cancer Institute. Per Hundred Thousand. NCI Thesaurus. Code C135516.

A unit, equal to one hundred thousand entities, is used as a denominator to build a derived unit expressed as a ratio. 